\title{
Structural Changes and Microstructure of Maraging Steel Lattice Structures using Additive Manufacturing
}

Pavel Hanzl, Ivana Zetková, Ludmila Kučerová

Faculty of Mechanical Engineering, University of West Bohemia. Univerzitní2732/8, 30614 Pilsen. Czech Republic.

E-mail: hanzlp@rti.zcu.cz, zetkova@rti.zcu.cz, skal@rti.zcu.cz

Direct Metal Laser Sintering (DMLS) is a method of additive manufacturing (AM), which builds metal parts in a layer by layer procedure based on a CAD template. The melting of metal powder by an energy beam and successful mastering of the whole manufacturing procedure requires complex management. Physical and chemical metallurgical phenomena occur during melting of the material and the final microstructure depends on many factors. This study investigates the microstructure of struts depending on their distance from the building platform. It is known that metal powder does not allow the dissipation of heat in the same way as molten material due to gas interstitial volume between the spherical particles. Metallography and micro-hardness were investigated on maraging steel 1.2709. Different melting strategies are recognizable in the macroscopic structure of metal alloys. Interesting facts have been discovered, for instance lose molten group or change of hardness depending on a shape of metal cells. In generally, significant differences were not found between individual specimens.

Keywords: Metal Additive Manufacturing, Cellular Lattice Structures, Metallography, Selective Laser Melting

\section{Introduction}

DMLS technology, which is one of the methods of Metal Additive Manufacturing (MAM), can produce high quality parts. This production is based on the melting of metal powder by a laser beam. This method allows the production of complex metal parts directly from 3D software models without using sometimes expensive tools such as moulds, dies and cutting tools.

In recent years, certain branches of the mechanical engineering industry have been increasing the weight of components. Metal Additive Manufacturing (MAM) opens new possibilities in the production of complicated components like lattice structures. Since the manufacturing is less constrained by the limits of traditional techniques, printed components can be smaller and more complicated. This is one of the reasons why the interest in additive manufacturing continues to grow.

The outcome of literature search is that Metal Additive Manufacturing (MAM) provides metal parts which often have much finer grains than molten or cast microstructures. Generally, this is attributed to very fast solidification of laser heated material. This happens due to the rapid conduction of heat from the molten zone into the surrounding metal.[1] There have already been researches that have been dealt with a investigation of influence of focused energy beam on the hardening of a metal substrate. [11]

Some materials are suitable for manufacturing using DMLS. This study is focused on W.Nr. 1.2709 maraging steel, which is an iron-nickel steel alloy with low carbon content. This alloy is used in applications where high strength and minimal changes of dimension are required. To achieve its strength and hardness, the maraging steel should be treated with an aging heat treatment. [6]

MAM products are characterized by their mechanical properties, which are affected by the settings of the process parameters. Some of these relationships are the focus of articles by Kempen et al. [7] and Yasa et al. [6], who studied the change of the integrity of materials produced with different combinations of process parameters. They describe how the laser power and scan speed affect mechanical properties and the structure of materials made from maraging steel 300 .

C. Yan et al. deal with the microstructure and mechanical properties of lattice structures. The material in their study was aluminium alloy. They found that compression strength and micro-hardness decreases as the unit size increases. The author notes for instance an increase in the compression strength by about $31 \%$ for $3 \mathrm{~mm}$ unit cell size compared with $5 \mathrm{~mm}$ size. In this case, the volume fraction was fixed at $15 \%$. The Vickers microhardness for a $3 \mathrm{~mm}$ cell unit size showed a $15 \%$ increase over the 7 $\mathrm{mm}$ cell unit. The microstructure becomes finer as the size of the cell unit decreases. [4]

The influence of processing conditions on strut structure was observed by Ch. Qui. It was found that the strut diameter increases with laser power due to the increase of the molten pool width. The porosity of molten aluminium alloy was largest at intermediate scanning speeds. Some combinations of scanning speed and laser power cause violent interactions between the laser beam and the molten track. This leads to increased surface roughness and internal porosity.[10]

Heat dissipation is generally very important for the resulting internal structure of a moulded, cast or lasermelted material, as [8], [9] and [2] prove in their research. These conclusions only confirm that DMLS is a complex physical metallurgical process. [3] It is well known that unmelted loose powder does not allow the dissipation of heat in the same way as molten material due to the gas interstitial volume between particles. In this context, a molten layer further from the platform could solidify under different conditions from a layer closer to zero level.

According to the research, this issue has not been dealt with in much detail for maraging steel. Therefore, this study investigates whether structural changes happen depending on the distance of the layer from the building platform. The experiment was performed on W.Nr. 
1.2709 maraging steel lattice structures, which were produced by DMLS. The cell unit for the structures was a "Schoen Gyroid" manufacture was stopped at several levels from the building platform. The aim of the study was to find and describe structural differences between crosssections of the levels. Detailed metallographic analyses with hardness measurements were carried out.

\section{Material and Methods}

The observed maraging steel (W.Nr. 1.2709) belongs into an iron-nickel steel alloy with low carbon content. The material composition is shown in Table 1. Powder for production of porous specimens was delivered by the EOS Company, which calls this material EOS MaragingSteel MS1. The porous specimens were produced by manufacturing systems on EOS M 290. This device uses $\mathrm{Yb}$-fibre laser for melting metal powder that reaches maximum power of $400 \mathrm{~W}$. Processing conditions of material printing were predefined by EOS. These parameters were set according the profile EOS DirectTool and the height of each layer was $40 \mu \mathrm{m}$.

Tab. 1 The material composition of EOS MaragingSteel MS1 [12]

\begin{tabular}{|c|c|c|c|c|c|c|c|c|c|c|c|c|}
\hline $\mathrm{t}[\%]$ & $\mathrm{Ni}$ & $\mathrm{Co}$ & $\mathrm{Fe}$ & Mo & $\mathrm{Ti}$ & $\mathrm{Al}$ & $\mathrm{Cr}$ & $\mathrm{Mn}$ & $\mathrm{P}$ & $\mathrm{S}$ & $\mathrm{C}$ & $\mathrm{Si}$ \\
\hline IS1 & $17-19$ & $8.5-9.5$ & rest & $4.5-5.2$ & $0.6-0.8$ & $0.05-0.15$ & $<0.5$ & $<0.1$ & $<0.01$ & $<0.01$ & $<0.03$ & $<0.1$ \\
\hline
\end{tabular}

Cell unit size and volume fraction are the basic parameters of lattice structures. The cell unit is defined by the lateral length of the cubic cell unit. The volume fraction of the solid phase expresses the percentage of the cell space which is filled by the material. [5] For the purpose of the experiment, both of the parameters were set as constant. The volume fraction was $7.3 \%$ and the cell size was set at $5 \mathrm{~mm}$. The set of samples consists of 3 levels (see Figure 1). The distance between adjacent levels was 10 $\mathrm{mm}$ and the first level was $4 \mathrm{~mm}$ from the building platform plane. The samples were inclined about $5^{\circ}$ from the vertical position in the process chamber. The struts on the upper surfaces of the samples had variable cross-sections. This procedure makes it easier to observe structural changes at different locations in the samples. The manufactured samples reached the typical quality of MAM and had no defects detectable by the naked eye.

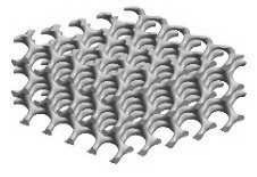

Level 1

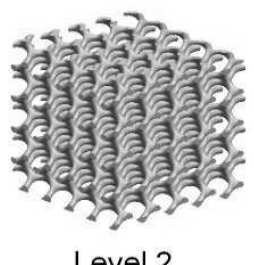

Level 2

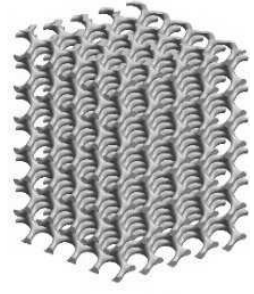

Level 3
Fig. 1 Height levels of samples

Metallographic specimens were prepared by mounting the samples in conductive resin. The top and bottom of the three porous specimens were analysed by light microscope Olympus BX 51. More detailed views of the microstructure were taken using a Zeiss Crossbeam Auriga scanning electron microscope. The observed areas of the specimens were polished and etched with $3 \%$ Nital. There were six specimens in total, which were also subjected to micro-hardness measurements (HV 0.01) using a UHL VMH-002V.

\section{Metallography and micro-structure}

Figure 2 (left) shows the strut microstructure on the bottom side, i.e. the side cut from the building platform. The location of the struts on this specimen side was closest to the building platform. Individual molten tracks are recognizable on the figure and the border between the core and skin is evident (see the arrow). The core of the sample is the solid volume of the constructional part that is surrounded by the skin layer. Both of these sample parts require different methods of melting. The contour is formed by only one laser track. Meanwhile, the core is hatched using other process parameters. The angle between the molten tracks in two neighbouring layers is $67^{\circ}$ as seen from the raster in the strut core. A detail of the core is shown in Figure 2 on the right. The microstructure of the thin strut is very similar to the volume material produced by the same printing technology. An exception is the multiple edge of the track that was observed in Figure 2 on the right (see the arrow). A detail of image from SEM in Figure 3 shows that fine cells are growing across this multiple edge/border.

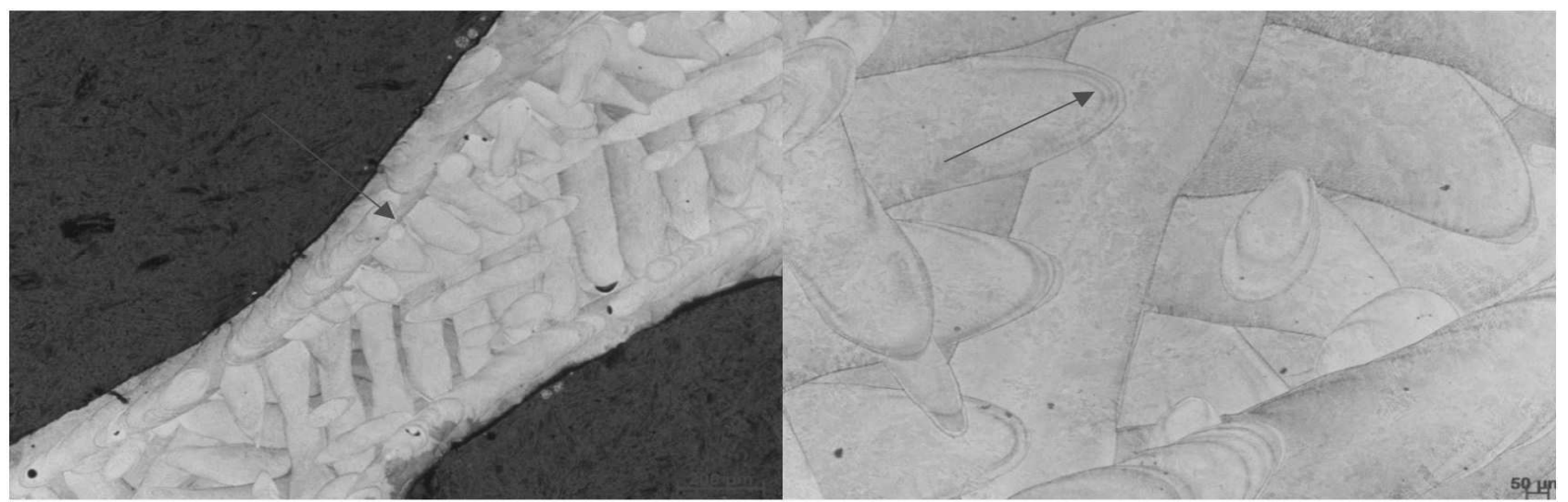

Fig. 2 Metallography of lattice strut; left-a clear border between the core and skin of the strut; right-the multiple edge of the track 


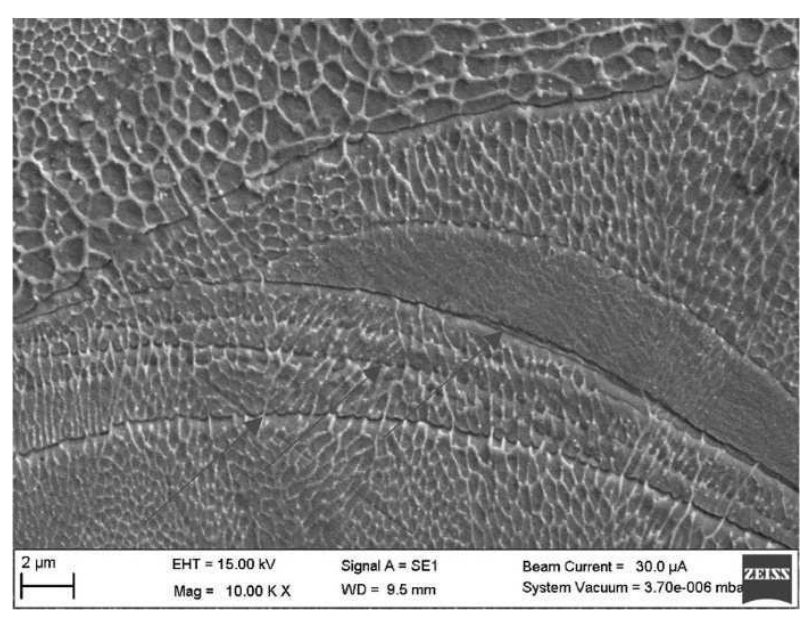

Fig. 3 Detail of the multiple edge of molten track

Melting of the upper sides finished at various levels. Therefore, there could be a possibility of microstructural change due to reduced cooling rate. It is well known that the dissipation of heat is less effective in unmelted powder with the gas interstitial volume between particles than in molten material. In this context, a molten layer further from the platform could solidify under different conditions from a layer closer to zero level. Figure 4 provides a look at the microstructures at $4 \mathrm{~mm}$ (level 1) and $24 \mathrm{~mm}$ (level 3). However, significant differences were not found in the microstructure of the individual specimens.

Free powder grains and groups of grains which did not hold together with the rest of the strut were commonly observed, as can be seen in Figure 5 on the left. Partially melted particles of the metal powder were in the edge zone of the strut, see Figure 5 on the right. The initial dendritic microstructure is evident inside the unmelted particle (see the arrow). Only full melting of the basic substrate and a high speed of the cooling can lead to the formation of the fine-grained structures which are typical for MAM of maraging steel.

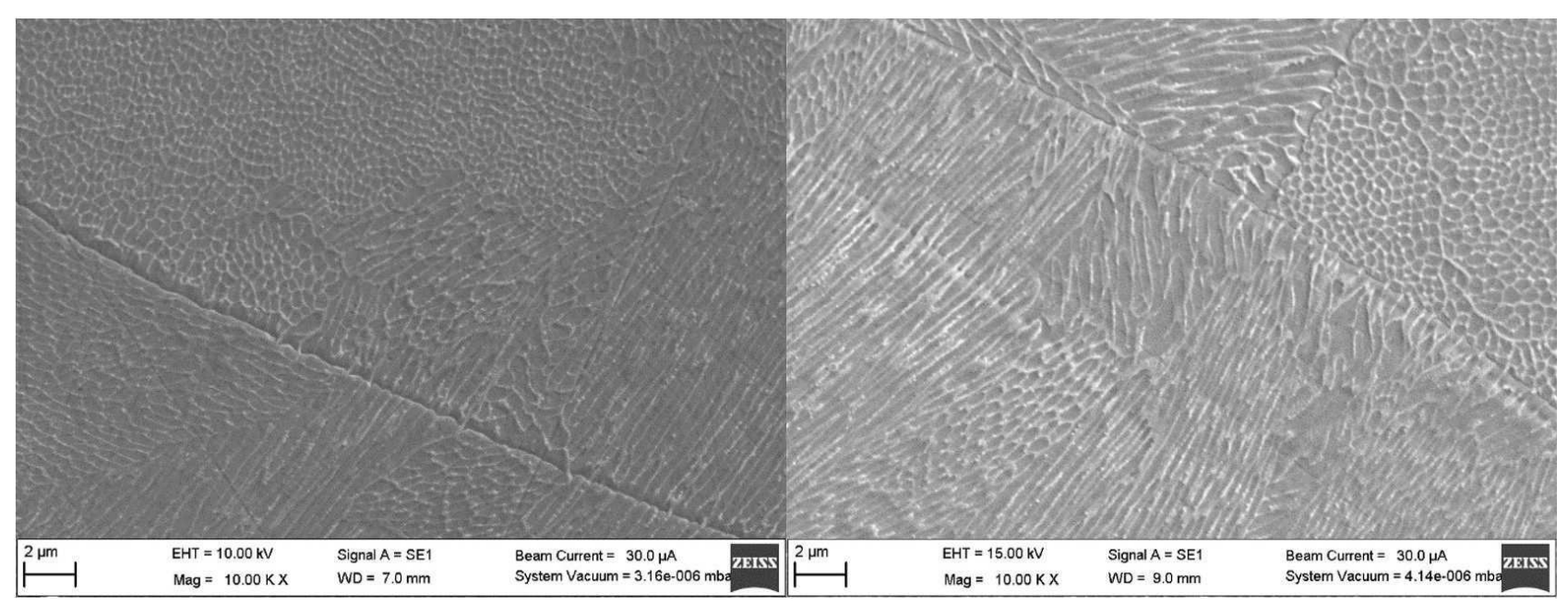

Fig. 4 Metallography of specimens; left - level 1 (4 mm); right level $3(24 \mathrm{~mm})$

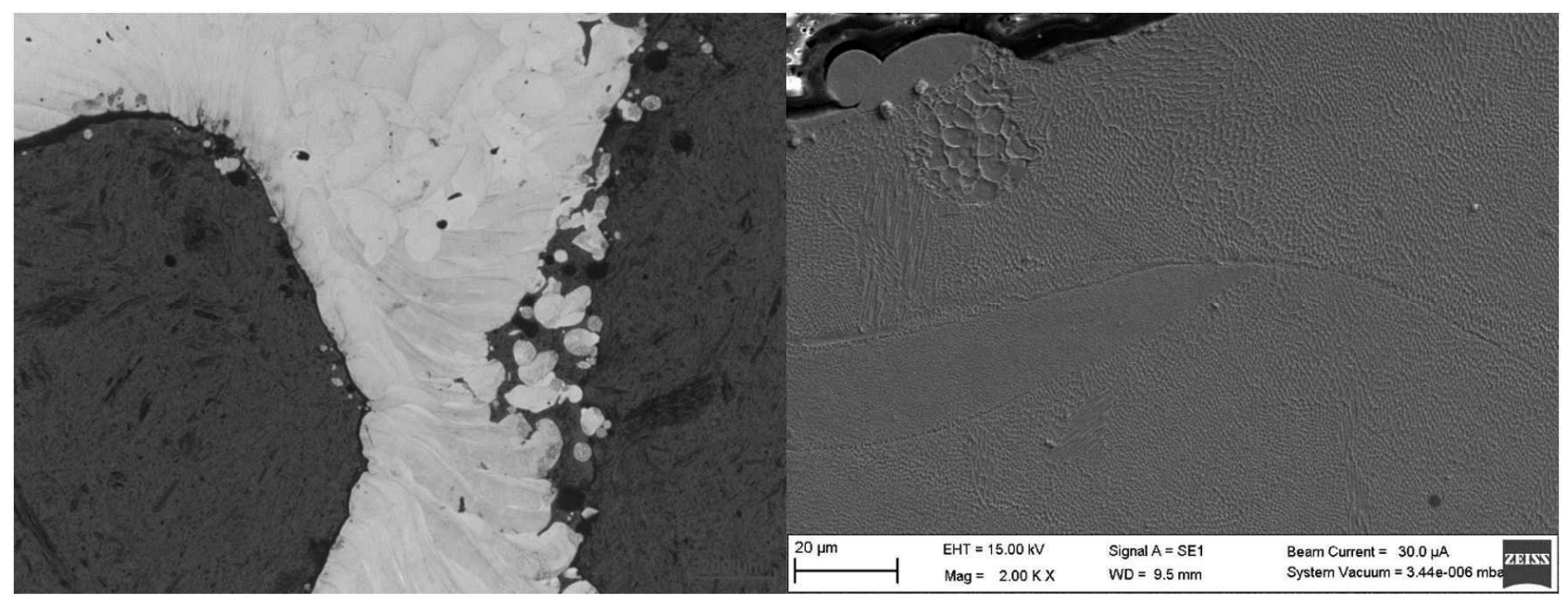

Fig. 5 Particles; left - loose molten group; right - swallowed particles with original dendritic structure

\section{Micro-hardness}

Micro-hardness HV 0.01 was measured to determine the effect of the cooling rate on the homogeneity of the material in the lattice structures across the cut of a gyroid strut. The results were very similar at the bottom and top of the three porous specimens. Figure 6 shows the values measured at the bottoms of the specimens. 


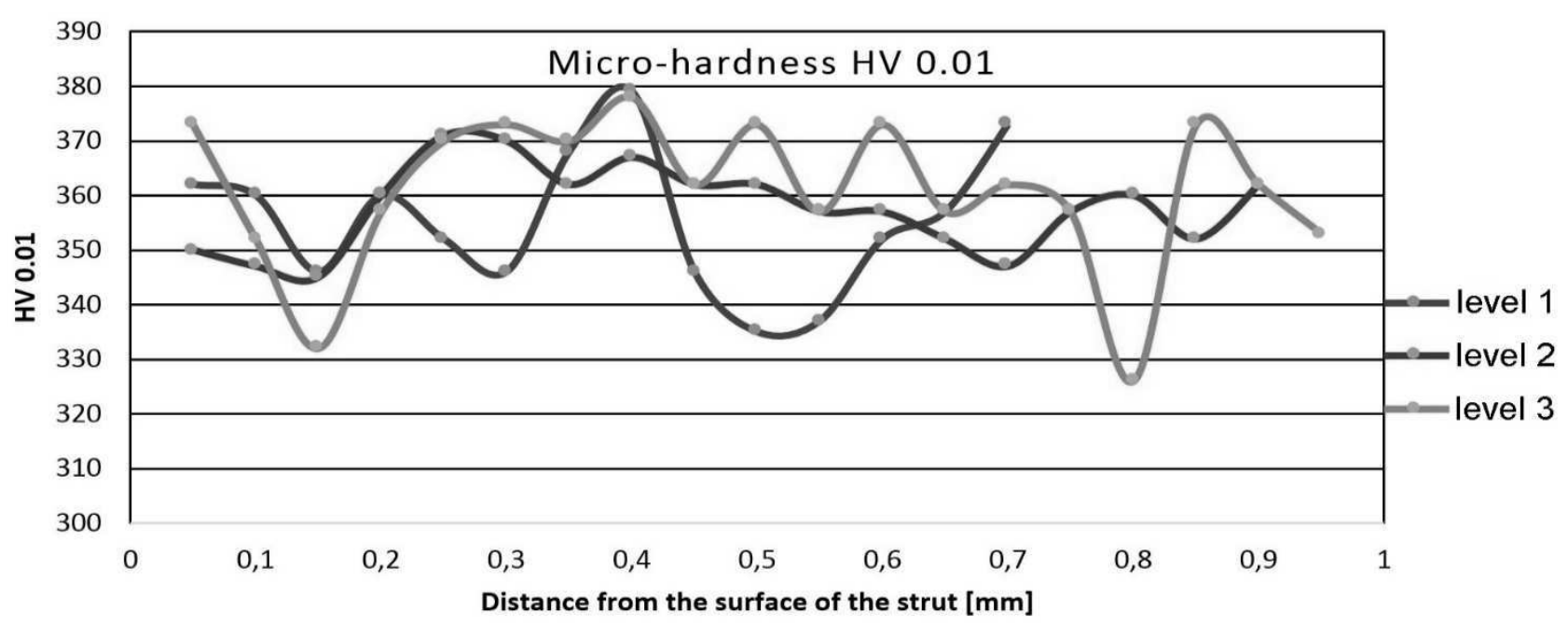

Fig. 6 Micro-hardness HV 0.01 of lattice specimens

According to the results, the edges of the struts do not have different properties from the strut middles. Individual levels are not different from each other. The microhardness for individual specimens are given in Table 2 where the arithmetical values and standard deviation ('SD') are listed.

Tab. 2 The results of hardness measurement

\begin{tabular}{lll}
\hline Specimen & Top & Bottom \\
\hline \multirow{2}{*}{1} & 357 HV 0.01; & 355 HV 0.01; \\
& SD =21 HV (level 1) & SD = 13 HV \\
\hline \multirow{2}{*}{2} & 308 HV 0.01; & $361 \mathrm{HV} \mathrm{0.01;}$ \\
& SD = 15 HV (level 2) & SD = 14 HV \\
\multirow{2}{*}{3} & 377 HV 0.01; & 357 HV 0.01; \\
& SD = 15 HV (level 3) & SD = 8 HV \\
\hline
\end{tabular}

In general, the local deviations in measurement were likely caused by pores which are present in the immediate vicinity of the apex of the puncture. However, the average micro-hardness is constant across the specimens except for specimen two at the top. There seems to be a reflection of the soft conductive resin into the measurements, since the metal base of the strut was very thin. The arithmetic hardness value was determined on $361 \mathrm{HV} 0.01(\mathrm{~s}=16$ HV 0.01). The measured hardness for specimen 2 at the top was not considered.

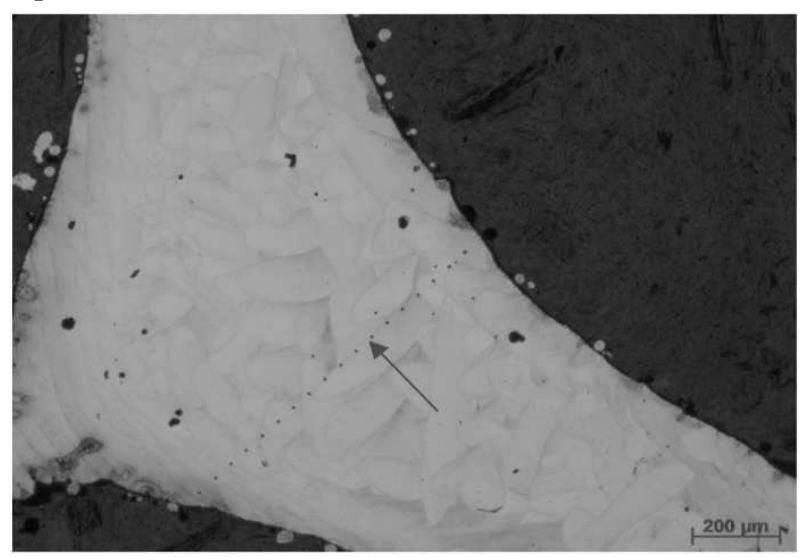

Fig. 7 Regions of micro-hardness measurement

It was further observed that the microstructure of a particular area could affect local hardness. For the same loading conditions, the hardness of the elongated cells (see puncture No.1 in Figure 8) was generally slightly higher than the hardness of the neighbouring areas of equiaxed cells (see puncture No.2 in Figure 8).

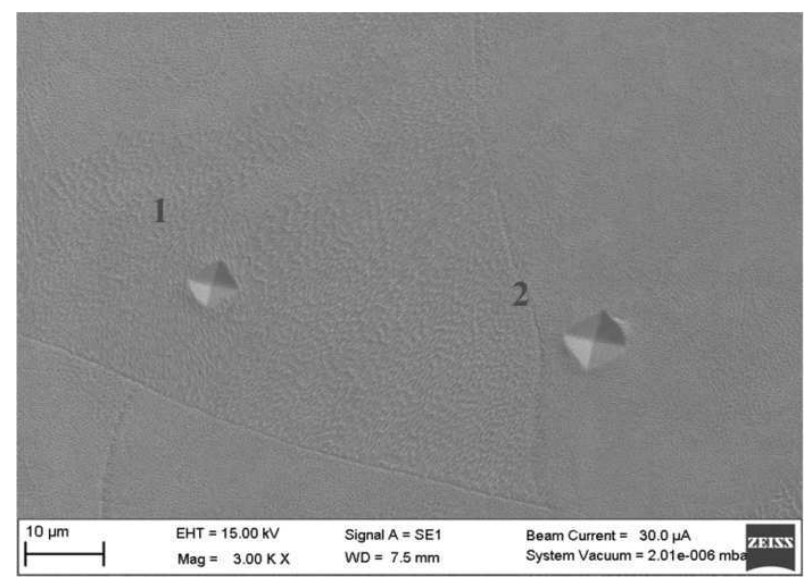

Fig. 8 Regions with different micro-hardness

\section{Conclusion}

This study investigated the microstructure and mechanical properties of 1.2709 maraging steel lattice structures at different levels from the building platform. Differences in microstructures were expected depending on the distance of the melted layer from the building platform due to the reduced heat transfer from the melted area. The smaller conductivity of the metal powder caused increasing temperatures in individual layers at a greater distance from the building platform. This is attributed to deteriorating heat transfer from the currently melted layer over the unmelted powder with the rising layer.

Therefore, structural changes to the maraging steel lattice structures were investigated at several levels from the building platform and detailed metallographic analyses with hardness measurements were carried out.

The microstructure of the thin molten material is very similar to the volume material made with the same or similar printing technology. In the result, a fine-grained structure was confirmed, which is in line with articles 
from Kempen et al. [7], Yasa et al. [6] and C. Yan et al. [4].

Two strategies of laser melting were observed on the metallurgical specimens; the contour and the core strategy. The contour forms the visible external surface of the struts and is melted by only one laser track. Meanwhile, the core is the centre of the struts and the hatching is rotated in two neighbouring layers by about $67^{\circ}$ from each other. This laser strategy should provide metal material with advantageous mechanical properties.

In all the specimens, elongated grains were contained in the fine-grained microstructure and there were no signs of higher porosity than is common for this steel classification produced by AM. A bigger count of free unmelted powder particles and their molten groups were found on the surface of the cell lattice structures. There were also partially melted particles which were firmly connected to the strut surface, but an initial dendritic microstructure with coarse grains was found inside them. The formation of these particles is attributed to the sharp angle of the building direction, which is determined as the slope melted the surface to the building platform. Complications occur when the building direction is less than $40^{\circ}$.

The same microstructures were observed in all of the metallurgical specimens. Micro-hardness measurement of the strut material depends on the local structure. This means that micro-hardness is influenced by the shape of the cells, cell size and, last but not least, by local defects such as pores. This conclusion did not support the effects of the distance from the building platform on the mechanical properties of the gyroid struts. This suggests that changes in the ability of heat transfer of the powder have a negligible effect on the microstructure. The temperature changes in individual layers (at heights from the building platform of $4 \mathrm{~mm}, 14 \mathrm{~mm}$ and $24 \mathrm{~mm}$ ) were not high enough to affect the microstructure. Structural changes could occur at a greater print height.

\section{Acknowledgement}

The present contribution has been prepared under project LO1502 'Development of the Regional Technological Institute' under the auspices of the National Sustainability Programme I of the Ministry of Education of the Czech Republic aimed at supporting research, experimental development and innovation.

\section{References}

[1] M. SHELLABEAR, O. NYRHILÄ Advances in materials and properties of direct metal laser-sintered parts, Available from: http://www.rm-platform.com/index 2 .php?option=com_docman\&task $=$ doc_view\&gid $=549 \&$ Itemid $=1$

[2] GU, D., SHEN, Y. (2008) Processing conditions and microstructural features of porous 316L stainless steel components by DMLS, Published by Elsevier Ltd, Applied Surface Science 255 (2008) 1880-1887
[3] GU, D., SHEN, Y. (2009) Balling phenomena in direct laser sintering of stainless steel powder: Metallurgical mechanisms and control methods, $\mathrm{Pu}-$ blished by Elsevier Ltd, Materials and Design 30 (2009) 2903-2910

[4] YAN, C., HAO, L., HUSSEIN, A., YOUNG, P., HUANG, J. (2015) Microstructure and mechanical properties of aluminium alloy cellular lattice structures manufactured by direct metal laser sintering, Published by Elsevier Ltd, Materials Science \& Engineering A 628 (2015) 238-246

[5] KHADERI, S. N., DESHPANDE, V. S., FLECK, N. A. (2013) The stiffness and strength of the gyroid lattice, International Journal of Solids and Structures, Volume 51, Issues 23-24, Pages 38663877, ISSN 0020-7683

[6] YASA E., KEMPEN, K., KRUTH, J.-P., VAN, H.J. (2010) Microstructure and mechanical properties of maraging steel 300 after selective laser melting, Catholic 21st Annual International Solid Freeform Fabrication Symposium - An Additive Manufacturing Conference, SFF 2010. 383-396.

[7] KEMPEN, K. et al. (2011) Microstrukture and mechanical properties of Selective Laser Melted 18Ni-300 steel, Physics Procedia, Volume 12, 2011, Pages 255-263, ISSN 1875-3892

[8] KEJZLAR, P., MACHUTA, J., NOVÁ, I. (2017) Comparison of the Structure of $\mathrm{CuZn} 40 \mathrm{MnAl}$ Alloy Casted into Sand and Metal Moulds, Published by Manufacturing Technology, ISSN 1213-2489, February 2017, Vol. 17, No. 1, Paper number: M20179

[9] ŠČŮRY, J., PASTIRČÁK, R. (2016) Effect of Technological Parameters on the Heat Transfer Coefficient in Alloy AlCu4Ti using Squeeze Casting Technology, Published by Manufacturing Technology, ISSN 1213-2489, June 2016, Vol. 16, No. 3, Paper number: M2016118

[10] QIU, Ch., YUE, S. et al. (2015) Influence of processing conditions on strut structure and compressive properties of cellular lattice structures fabricated by selective laser melting, Materials Science and Engineering: A, Volume 628, 2015, Pages 188-197, ISSN 0921-5093

[11] MATLÁK, J., DLOUHÝ, I. (2018) Properties of Electron Beam Hardened Layers made by Different Beam Deflection, Published by Manufacturing Technology, April 2018, Vol. 18, No. 2, Pages 279-284, ISSN 1213-2489

[12] EOS MaragingSteel MS1, EOS, online [2018-0807], available from: https://cdn.eos.info/1deee2b550955632/b3615b8 0c80a/MS-MS1-M290_Material_data_sheet_1017_en.pdf 